\title{
Early growth faltering in post-institutionalized youth and later anthropometric and pubertal development
}

\author{
Brie M. Reid ${ }^{1}$, Bradley S. Miller ${ }^{2}$, Lorah D. Dorn ${ }^{3}$, Christopher Desjardins ${ }^{4}$, Bonny Donzella ${ }^{1}$ and Megan Gunnar ${ }^{1}$
}

BACKGROUND: Early-life adversity that increases the risk of growth stunting is hypothesized to increase the risk of obesity and, in girls, early-onset puberty. This hypothesis was tested in children adopted from orphanages.

METHODS: Post-institutionalized (PI) youth were compared with youth reared in comparable families (non-adopted; NA) on height, weight, pubertal stage, and fat mass $(127 \mathrm{Pl}, 80$ female; 156 NA, 85 female, aged 7-14 years). Anthropometric findings at adoption were obtained from first US clinic visits.

RESULTS: Overall, 25\% of PI youth were height-stunted $(<3$ rd percentile) at adoption. Years post adoption, PI youth had lower BMl-for-age $(P=0.004)$, height-for-age $(P<0.001)$, and less body fat $(P<0.001)$ than NA youth had, but they did not differ by sex. Pubertal status did not differ by group or sex. The anthropometric findings held when the stunted-atadoption subset was examined; they were also less likely to be in central puberty than other PI youth.

CONCLUSION: Early deprived orphanage care increases the risk of growth stunting but not obesity in children adopted into US families, and it does not independently contribute to early-onset puberty for PI girls. The role of the environment following early adversity may modify the impact of early adverse care.

$T$ hroughout evolution, humans have experienced periods of feast and famine. There is evidence that early in development, physiological adaptations to deprived environments increase later risks of obesity, early-onset puberty in girls, and, later, metabolic syndrome and cardiovascular disease, particularly if there is a shift over time from resource-poor to resource-rich environments (1-4). Studies of maltreated children and youth reveal that similar effects of childhood adversity on pubertal timing and obesity risk may result even when adversity is psychosocial (5-7). Here, it may be that continued adversity, such as low socioeconomic status, enhances risk.

Children adopted from orphanages (post-institutionalized; PI) provide an interesting case to test hypotheses about the sequelae of early adversity. Institutional care early in life typically results in significant delays in height and weight, as well as delays in other domains of development (8-11). These delays are correlated with reductions in psychosocial care and are observed even when the nutritional content of feedings is adequate. Propped bottles and stress-impaired absorption of nutrients are also likely contributors to poor growth for institutionalized infants and young children $(8,12)$. With adoption into families in industrialized countries, these children make a radical shift from conditions of low to high psychosocial and physical resources. They typically experience rapid catch-up growth in height and weight, and are typically within normal height and weight ranges within a year or two of adoption $(8,11)$. Clinically, there is concern that PI children with rapid catch-up growth may be at a higher risk for obesity, early-onset puberty in girls, and, in adulthood, for metabolic syndrome (9).

Research on postnatal growth trajectories in typically developing children suggest that being small at birth but having a large body mass as an adult is associated with a high risk of disease $(13,14)$. There is some evidence to suggest that the physiological mechanisms of catch-up growth promote the accumulation of body fat after nutritional deprivation (15). Studies of children in low- and middle-income countries show that early postnatal catch-up growth is associated with obesity and risk for metabolic syndrome later in life $(2,16)$. Robust catch-up growth prevalent in children adopted internationally is a risk factor for later obesity and earlyonset puberty, both of which are risk factors for cardiovascular diseases, type-2 diabetes, and musculoskeletal disorders (17). Early puberty is also associated with sexually transmitted diseases and teenage pregnancy in girls, smoking and aggressive behavior in boys, adolescent alcohol abuse and drug use, and early sexual debut in both sexes (18-20).

There is some evidence that clinical concerns for PI children may be substantiated. Girls from India adopted into Sweden were found to have earlier menarche if they were growth-stunted at adoption and experienced rapid catch-up growth (21). Looking only at children seen for precocious puberty in Sweden, international adoption after age 2 was

\footnotetext{
${ }^{1}$ Institute of Child Development, University of Minnesota, Minneapolis, Minnesota; ${ }^{2}$ Division of Pediatric Endocrinology, Department of Pediatrics, University of Minnesota, Minneapolis, Minnesota; ${ }^{3}$ College of Nursing and Department of Pediatrics, The Pennsylvania State University, University Park, Pennsylvania; ${ }^{4}$ Center for Applied Research and Educational Improvement, University of Minnesota Twin Cities, Minneapolis, Minnesota. Correspondence: Brie M. Reid (reidx189@umn.edu)

Received 9 October 2016; accepted 7 January 2017; advance online publication 24 May 2017. doi:10.1038/pr.2017.35
} 


\section{Puberty and growth in post-institutionalized youth 1 Articles}

associated with a marked increase in risk of precocious puberty (22). The rate of central precocious puberty in the population is 1 in 5,000 to 10,000 children, but it is much more common (10 to 1 ratio) in girls than in boys (23) and has an increased incidence $(0.8-1.8 \%)$ in internationally adopted children (24). However, in at least one study, the risk of precocious puberty was as great for immigrant children without evidence of early growth stunting from the same regions of the world, which suggests the possibility that changes in diet that occur after immigration could influence pubertal status; alternatively, early exposures to endocrine disruptors might be involved (25). In contrast to these studies, a recent study in girls adopted from China into North America found that adopted girls had similar age at menarche to their non-adopted peers (26). Although internet surveys of parents of internationally adopted children have yielded evidence of precocious puberty, accuracy of pubertal stage cannot be determined in such surveys nor can the percentage of families responding be determined (27).

In this study, we examined and compared height, weight, and pubertal stage in PI children aged 7 to 14 years with those in children born into homes comparable in parental education and income to the homes of the PI youth (NA). We also examined the impact of height stunting at adoption on growth and pubertal status within the PI youth. Our goal was to test the hypothesis that a shift from psychosocial and physical deprivation to highly resourced homes would increase the risk of obesity in boys and girls and, for girls, advanced pubertal timing. We predicted that this would be most clearly observed for PI youth who were stunted at adoption.

\section{METHODS}

\section{Study Population}

PI youth were recruited from a registry of internationally adopting families interested in research participation. NA youth were recruited from a registry of research-interested families with comparable education and income to adoptive families. Both PI and NA youth lived within driving distance of Minneapolis, MN. Exclusion criteria for PI youth were adoption from institutions after 60 months of age, facial indices of fetal alcohol exposure using the FAS Facial Photographic Analysis software, and congenital and endocrine disorders. Comparison children were excluded if they experienced early adversity as determined by early-life maltreatment or neglect, or if they had been diagnosed with neurodevelopmental disorders. All procedures were approved by the University's institutional review board. Written informed consent was obtained from parents, and written informed assent was obtained from the children.

\section{Measurements and Protocol}

Anthropometrics. Height- and weight-for-age at adoption was obtained from PI children's first pediatric visit after entering the US. Parents signed HIPAA release forms and provided their child's providers name and address. As some clinics reported that the early adoption data were missing from their files, 109 of 127 PIs data were obtained. Early-life growth faltering (stunting) was defined as a height-for-age equal to or below -2 standard deviations from the mean of the WHO reference group (i.e., $<3$ rd percentile -height-forage) at adoption (28).

A nurse trained in auxology measured height in triplicate to the nearest $0.1 \mathrm{~cm}$ using a calibrated stadiometer (SECA model 216, Seca
Hanover, MD) and weight to the nearest $0.1 \mathrm{~kg}$ using a calibrated scale (Health-O-Meter Professional 349KLX Professional Medical Weight Scale, Pelstar LLC, McCook, IL). If there was a discrepancy between the measurements in triplicate, the mean score was taken. To compare children of different ages, height and BMI (weight in kg/ height in $\mathrm{m}^{2}$ ) measurements were converted to $z$-scores (the difference between the child's measurement and the age mean divided by the standard deviation (SD) for the child's age). We calculated age-sex-adjusted BMI $z$-score and -height-for-age $z$-score using the 2007 World Health Organization reference data, which is comprised of growth data from widely different ethnic backgrounds and cultural settings around the world (28). Waist and hip circumferences $(\mathrm{cm})$ were measured in triplicate with an anthropometric tape while the participants were wearing light clothing. Waist circumference was measured one inch above the navel. Hip circumference was measured at the maximum protuberance of the buttocks. The WSR was calculated by dividing the waist $(\mathrm{cm})$ by the height $(\mathrm{cm})$. Body fat percentage was measured in the BOD POD (Life Measurement Instruments, Concord, CA), a 2-chamber air displacement plethysmograph method of determining body fat percentage and body volume through a software-driven automated test (29). The BOD POD was calibrated before each test following the manufacturer's recommendations. Participants wore a tight-fitting swimsuit or biking shorts, and a swim cap, and remained seated in the chamber during the measurement.

Pubertal development. Study nurses received Tanner stage training from an expert in performing this assessment in clinical trials and a pediatric endocrinologist. A total of 264 participants underwent a nurse's exam for Tanner Staging (range $1-5, M=2.48, \mathrm{SD}=1.51$ ). In total, $6 \%(n=17)$ of youth refused the Tanner stage exam and had pubertal development scores estimated from self-reported Petersen Pubertal Development Scale. Three pediatric endocrine nurses conducted a physical exam to measure pubertal stage using Marshal and Tanner criteria (30,31). Cohen's $\kappa$ was run to determine whether there was an agreement between the three nurses' Tanner stage assessment on breast and genital measures in 33 boys and 50 girls. There was almost perfect agreement between the nurses' assessments, $\kappa=0.87, P<0.001$ using Landis and Koch criteria of $>0.81$. In girls, breast and pubic hair stage was determined by visual examination, and the nurse palpated breasts to distinguish breast from adipose tissue. In boys, genital and pubic hair stage was determined by visual examination, and the nurse determined testicular volume using a Prader orchidometer. Tanner breast stage in girls and genital stage in boys was used to determine entry into central puberty, as these indicators are most indicative of central puberty. Central puberty was therefore defined as Tanner stage 2 in breasts for girls and Tanner stage 2 genital for boys $(4 \mathrm{ml})$, using the most developed breast or testicle measured. Central precocious puberty was defined as Tanner breast stage 2 before age 8 years in girls and Tanner genital stage 2 before age 9 years in boys. "Early-onset" puberty was defined as the onset of puberty (Tanner stage 2) in girls between 8 and 10 years of age and in boys between 9 and 11 years of age (24). Delayed puberty was defined as not reaching Tanner breast stage 2 by age 14 for girls and not reaching Tanner genital stage 2 by age 15 for boys (24).

Pubertal status was also assessed using a self-report from the child and parent of body changes associated with puberty using the Pubertal Development Scale $(32,33)$. For boys, measures included growth in height, body hair, skin changes, deepening of voice, and facial hair. For girls, measures included growth in height, body hair, skin changes, breast development, and onset of menarche. Responses were as follows $-1=$ not yet started, $2=$ barely started, $3=$ definitely started, and $4=$ seems complete (32). Menstruation was coded as 4 if it begun and as 1 if it had not begun, alongside a self-report of age in months of menarche. This measure yields a mean score from 1 (puberty has not begun) to 4 (puberty is complete). 


\section{Data Analysis}

Preliminary analysis of missing data from adoption clinic visits with Little's MCAR test indicated that the early growth data was missing completely at random. Analyses were then conducted in four parts. First, descriptive statistics were examined and independent samples $t$-tests were conducted to examine group differences in participants' age and growth. Then, a $\chi^{2}$ test was used to determine group differences in early-onset puberty compared with typical onset puberty. Fisher's exact test was used to determine the association between group and precocious puberty for PI and NA youth. Fisher's exact test was also used to determine the association between earlylife height stunting or no early-life height stunting in PI youth and Tanner stage 1. Finally, we used a proportional odds model to determine the effect of BMI, age, gender, and group on Tanner stage. We assessed the parallel regressions assumption model by fitting a partial proportional odds model and assessing the change in model fit using a test of a deviance. We found that BMI and age met the parallel regressions assumption but gender and group did not. However, because gender and group were not statistically significant, overall, they were dropped from the model; and the model presented in the results section was from the proportional odds model with $\mathrm{BMI}$ and age.

\section{RESULTS}

Demographic and anthropometric results are shown in Table 1. Study participants were 7 to 14 years old $(M=11.16, \mathrm{SD}=2.30)$. Overall, 127 (80 females) participants were adopted internationally from orphanages (PI) and 156 (85 females) participants were NA youth. PI youth were from 14 countries (54 from Russia, 23 from China, 16 from India, 8 from Guatemala, 5 from Colombia, 4 from Ethiopia, 4 from Ukraine, 4 from Vietnam, 2 from Haiti, 2 from Kazakhstan, 2 from Solvakia, 1 from Ecuador, 1 from Nepal, and 1 from Romania), PI youth were also from a range of racial and ethnic backgrounds-49 Asian, 52 Caucasian, 6 Black/African, 13 Latin American Indian, 4 multiracial, and 3 other/unknown. NA youth were born in the US (1 Asian, 139 Caucasian, 4 Black, 11 multiracial, and 1 other/unknown). Age did not differ between groups. Household income also did not differ between groups with a median household income of $\$ 85,001-\$ 100,000$ (range $\$ 25,000$ to $>\$ 200,000$ ).

At adoption ( $M=19.8$ months old, $\mathrm{SD}=12.6$ months), the PI youth were below norms on height-for-age ( $z$-score, $M=-1.12, \mathrm{SD}=1.46$ ) and weight-for-age ( $z$-score, $M=$ $-0.92, \mathrm{SD}=1.15)$, with $43 \%$ being below the 10 th percentile in height-for-age and $24 \%$ being classified as growth-stunted (below the 3rd percentile). The PI youth displayed the expected catch-up growth such that, by the time of our assessment, $5 \%$ were stunted and $72 \%$ were above 1 SD below the mean on height and weight.

\section{Anthropometrics}

PI youth were shorter than the NA youth, on average, at assessment. In contrast to predictions, we found no evidence that PI youth were heavier than NA youth. Indeed, PI youth had lower BMI values than NA youth had (Figure 1). At time $1,11.8 \%$ of PI children were overweight (BMI $>85$ th percentile) and $7.9 \%$ were obese (BMI $>95$ th percentile). A total of $15.4 \%$ of NA children were overweight (BMI $>85$ th percentile) and $7.1 \%$ were obese (BMI $>95$ th percentile). Both
Table 1. Anthropometric and pubertal stage data in PI and NA children at exam 1

\begin{tabular}{|c|c|c|c|}
\hline Characteristics & $\begin{array}{c}\text { Post- } \\
\text { institutionalized; PI } \\
(n=127)\end{array}$ & $\begin{array}{l}\text { Non-adopted; NA } \\
\quad(n=156)\end{array}$ & $P$ \\
\hline & Mean \pm SD & Mean \pm SD & \\
\hline Female & $n=80(63 \%)$ & $n=85(54.5 \%)$ & $0.149^{*}$ \\
\hline Age (years) & $11.24 \pm 2.41$ & $11.10 \pm 2.22$ & $0.629^{*}$ \\
\hline Height $(\mathrm{cm})$ & $143.09 \pm 15.09$ & $146.74 \pm 15.43$ & - \\
\hline $\begin{array}{l}\text { Height-for-age } \\
\text { (z-score) }\end{array}$ & $-0.37 \pm 1.06$ & $0.30 \pm 1.02$ & $0.005^{* *}$ \\
\hline Weight $(\mathrm{kg})$ & $37.53 \pm 12.39$ & $41.50 \pm 15.55$ & - \\
\hline BMI & $17.85 \pm 3.35$ & $18.64 \pm 0.94$ & - \\
\hline $\begin{array}{l}\text { BMI-for-age ( } z \text { - } \\
\text { score) }\end{array}$ & $-0.08 \pm 1.31$ & $0.33 \pm 1.08$ & $0.005^{* *}$ \\
\hline $\begin{array}{l}\text { Body fat } \\
\text { percentage }\end{array}$ & $15.55 \pm 9.15^{a}$ & $19.18 \pm 9.06$ & $0.001^{* * *}$ \\
\hline Waist (cm) & $61 \pm 9.44$ & $63.50 \pm 10.68$ & - \\
\hline Hip (cm) & $74.24 \pm 10.43$ & $76.70 \pm 11.90$ & - \\
\hline Waist to hip ratio & $0.82 \pm 0.07$ & $0.83 \pm .07$ & $0.393^{*}$ \\
\hline $\begin{array}{l}\text { Waist to stature } \\
\text { ratio }\end{array}$ & $0.43 \pm 0.05$ & $0.43 \pm 0.05$ & $0.362^{*}$ \\
\hline
\end{tabular}

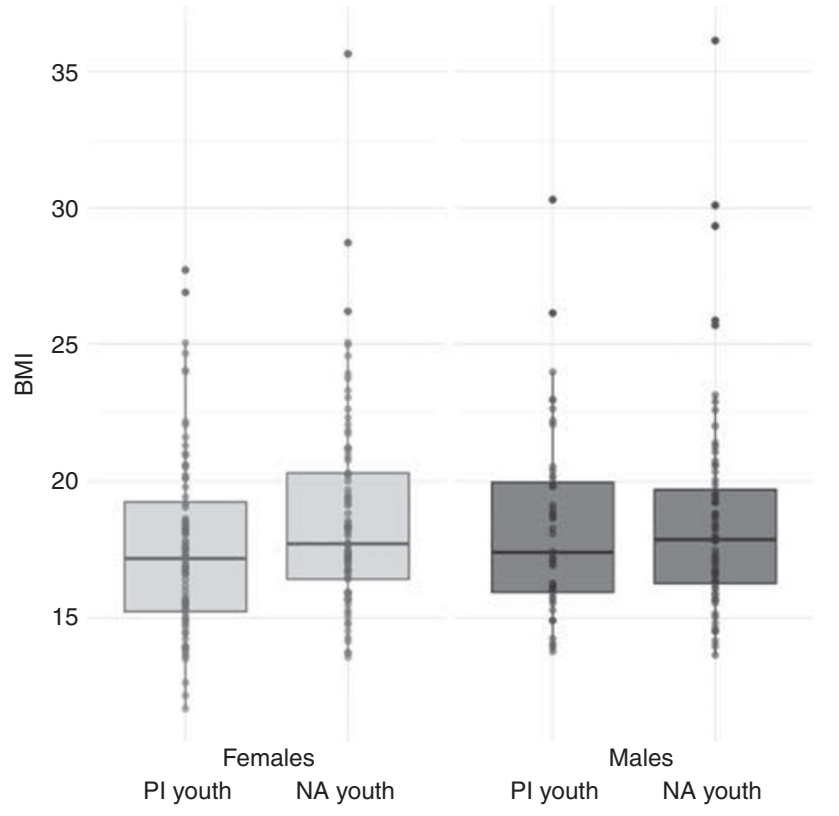

Figure 1. Body mass index (BMI) of post-institutionalized (PI) and comparison (NA) youth. Female youth are compared in the left panel, whereas male youth are compared in the right panel. Dark gray boxplots represent NA youth, whereas light gray boxplots represent PI youth.

groups fell below rates of overweight (14.9\%) and obesity (16.9\%) in US children, but were roughly comparable with percentages for their socioeconomic group (34). PI youth also had lower body fat percentages measured by air displacement 


\section{Puberty and growth in post-institutionalized youth}

plethysmography than NA youth had. This held even when we removed 9 implausible cases with body fat below $3 \%$; $t(271)=-2.82, P=0.005$.

There was also no evidence that weight was being preferentially stored in the gut, as waist-hip ratios and waist-to-stature ratios (WSR) did not differ between PI and NA youth. The effect sizes of the differences found between the two groups were large for height-for-age $(d=0.64)$ and moderate for -BMI-for-age $(d=0.35)$ and body fat percentage $(d=0.40)$. Additional analyses assessed the data to determine whether girls might be showing the early adversity-obesity effects; however, none of the measures were significantly different for PI girls. Finally, although some children (5 PI, $4 \%$; $5 \mathrm{NA}, 3 \%$ ) were taking stimulant medication for Attention-deficit/hyperactivity disorder (ADHD), which can affect growth and weight gain, adding stimulant use as a covariate had no effect on these findings.

\section{Pubertal Development}

Table 2 shows the results for pubertal stage with the full range of Tanner stages noted for both PI and NA youth. We predicted that PI children as a group would be in later Tanner stages to indicate either earlier onset or a more rapid tempo of pubertal development than NA children. Although one PI girl displayed signs of precocious puberty, there was no statistically significant association between PI status and precocious puberty as assessed by Fisher's exact test, $P=0.170$. No children were in early-onset puberty. Furthermore, no children were in delayed puberty, and a $t$-test showed no difference in self-reported age at menarche between PI and NA girls.

A proportional odds model was run to determine the effect of group (PI or NA), sex, BMI, and age on pubertal status (Tanner stage). We found a main effect of BMI and age, but found no evidence of an effect from sex or group membership. An increase in age (expressed in years) was associated with an increase in the odds of higher Tanner stage, with an odds ratio of 3.418 (95\% confidence interval (CI) 2.8204.143), $\chi^{2}(1)=156.80, P<0.001$ (Figure 2). An increase in BMI was associated with an increase in the odds of higher Tanner stage, with an odds ratio of 1.159 (95\% CI 1.0711.253), $\chi^{2}(1)=13.61, P<0.001$. The results did not differ

Table 2. Anthropometric and pubertal stage data in PI and NA children

\begin{tabular}{|c|c|c|c|}
\hline Characteristics & $\begin{array}{l}\text { Post-institutionalized; } \\
\text { PI }(n=127)\end{array}$ & $\begin{array}{l}\text { Non-adopted; } \\
\text { NA }(n=156)\end{array}$ & $P$ \\
\hline & $\begin{array}{c}\text { Mean } \pm \text { SD } \\
\text { Median (range) }\end{array}$ & $\begin{array}{c}\text { Mean } \pm \text { SD } \\
\text { Median (range) }\end{array}$ & \\
\hline Tanner stage & $2(1-5)$ & $2(1-5)$ & 0.536 \\
\hline $\begin{array}{l}\text { Number of } \\
\text { menarcheal girls }\end{array}$ & $16(20 \%)$ & $23(27 \%)$ & 0.327 \\
\hline $\begin{array}{l}\text { Age of onset of } \\
\text { menstruating } \\
\text { (years) }\end{array}$ & $11.70 \pm 1.64^{\mathrm{a}}$ & $12.09 \pm 1.29^{b}$ & 0.408 \\
\hline
\end{tabular}

when using the WHO-adjusted metric of BMI-for-age, and thus raw BMI is reported for ease of interpretation. As there was no group or sex difference found in pubertal stage, these data were inconsistent with our prediction that PI girls would be more likely to enter puberty earlier than non-adopted peers.

\section{Anthropometric and Pubertal Development in Previously Stunted Post-Institutionalized Youth}

The 26 children who had been growth-stunted at adoption were not different in age at adoption or sex than their nonstunted PI peers. Notably, previously stunted PI youth had greater height catch-up growth than their non-stunted peers; $t(107)=6.89, P<0.001$. Rather than being prone to obesity, previously growth-stunted PI youth did not exhibit greater fat mass or BMI-for-age. Two youth who were previously stunted at adoption were overweight at follow-up (8\%), whereas 18 non-stunted at adoption PI youth were overweight or obese at follow-up (22\%). Previously stunted youth were also still shorter for age than the non-stunted PI youth; $t(107)=3.05$, $P=0.003$.

Of the previously height-stunted PI youth, 15 (57.7\%) were in Tanner stage 1 compared with all other Tanner stages at follow-up. For previously non-height-stunted PI youth, 25 (30.1\%) were in Tanner stage 1 compared with all other Tanner stages. There was a statistically significant association between prior height-stunted status and Tanner stage 1 as assessed by Fisher's exact test, $P=0.011$. However, linear catch-up growth was not associated with Tanner stage 1.

\section{DISCUSSION}

The results of this study provided no support for the hypothesis that significant adversity and growth stunting early in life would increase risk of obesity and, for girls, earlyonset puberty. Instead of finding greater BMIs, fat mass, and waist-hip ratios in the PI than in NA youth, PI youth had lower BMI values and fat mass, and they did not differ from NA youth in waist-hip ratio. No sex by group effects were noted; thus these findings held for both girls and boys. The results for pubertal development also did not support the early adversity-early puberty hypothesis. Similar to a recent study of girls adopted from China, we did not find a difference in the timing of menarche between PI and NA children (26). Our growth data are also similar with those of Walker, Chang, and Powell, who reported that previously stunted Jamaican children remained shorter and had lower BMI values and smaller body fat percentages than nonstunted Jamaican children in late adolescence (35). Although PI children were, on average, shorter and thinner than their non-adopted peers in body fat and BMI measures, the WSR for PI and NA children did not differ significantly. Both groups' WSRs were well below the at-risk cutoff of 0.5 (36).

Our results comparing previously stunted PI children to non-stunted PI children demonstrate that catch-up growth post adoption was not associated with any measures of pubertal development or early-onset puberty. Perhaps, the 


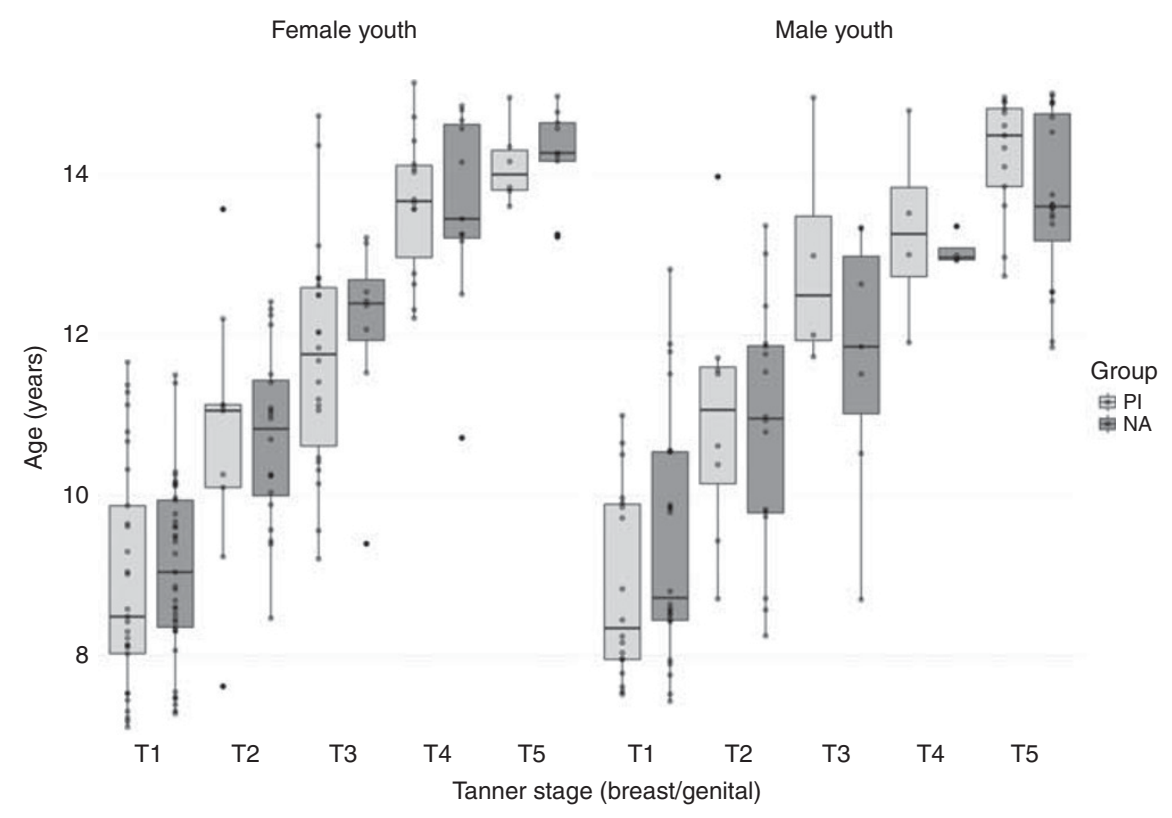

Figure 2. Tanner stage of post-institutionalized (PI) and comparison (NA) youth. Female youth are compared in the left panel, whereas male youth are compared in the right panel. Dark gray boxplots represent NA youth, where light gray boxplots represent PI youth.

cohort of children adopted internationally in our study, adopted before 5 years of age into highly resourced homes in the US, were adopted early enough or had medical care or home environments that helped to mitigate risks of rapid catch-up growth. The risk of robust catch-up growth post adoption might not have been captured by our measure of catch-up growth. Rapid catch-up growth is an ill-defined concept in many studies, which further complicates comparison of catch-up growth outcomes between cohorts that are of different age ranges and ethnicities (16). A recent twin study found that an obesogenic postnatal environment is more important than the fetal environment for the development of increased adiposity (37), and thus our sample of high socioeconomic status (SES) families might mitigate any risk for future obesity and early-onset puberty by providing a health-conscious environment for otherwise at-risk PI children. Both PI and NA youth groups had low rates of obesity compared with national standards in the US (34). Early onset of puberty in at-risk youth might be critically related to the obesogenic environment and adiposity levels necessary for pubertal hormones. The work of Addo et al. (38) shows that postnatal weight gain is a crucial factor in early pubertal development, making a lack of post-adoption weight gain one potential reason for the absence of earlier puberty in our previously stunted study population.

Although this study has the strengths of pubertal stage by exam and use of the Bod Pod to determine growth and pubertal status of PI and NA youth rather than relying upon self- or parent report, this study had several limitations. The data were the initial data from a study that will follow children across three annual assessments. Thus, it is possible that more evidence of precocious puberty will emerge as the children progress through the study. Although another definition of delayed puberty is defined as Tanner breast stage 2 with no menarche by age 16 , no children in this sample were 16 years old or older, and thus delayed puberty defined by menarche could not be established. Future waves of data collection will enable us to better characterize development both in anthropometric measures and pubertal measures over time in the same cohort of children. However, as many have hypothesized that post-institutionalized and stunted children-and especially girl children-will have early-onset puberty and greater risk of obesity, this study suggests that stress and growth stunting early in life do not necessarily increase the risk of obesity or early puberty in the context of a major intervention, adoption by highly educated and resourced parents. Although we have only a single case of precocious puberty in our cohort ( 1 out of $127=0.8 \%$ ), this is in agreement with previous reports $(0.8-1.8 \%)$ in internationally adopted children (24), and the association between precocious puberty and PI status was not statistically significant.

We also were unable to collect adoption-age-equivalent growth data for NA youth to compare their outcomes with previously height-stunted PI and non-previously heightstunted PI youth. However, as the rate of height stunting is exceedingly low in industrialized countries, we would not expect NA youth from highly resourced homes to have experienced height stunting early in life.

Second, for the smallest children, low body fat percent scores might not be accurate due to the Bod Pod's methods of calculating body fat percentage, which is normed to typically developing children and may overestimate both the thoracic volume and bone density of children who are smaller in stature to result in unusually low body fat percentage scores. Other means of measuring body fat percentage, such as dualenergy X-ray absorptiometry, might be needed to further 


\section{Puberty and growth in post-institutionalized youth $\quad$ Articles}

clarify the relationship between early-life adversity and body fat percentage. However, even after removing the leanest Bod Pod measurements, the effect size remained between PI and NA children's body fat percentage scores, suggesting that PI children do indeed have lower percentages of body fat. However, cardiovascular risk depends not only on the percent of fat but where the fat is located (39). It is possible that for PI youth, fat is more likely to be concentrated in the gut. This will need to be assessed in future studies, although we should note that the waist-hip ratio was not greater for PI than NA children in this report. Conversely, PI youth might have metabolic abnormalities even in the face of normal BMI ranges (40). Hence, these data do not necessarily argue that the cardiovascular and metabolic risk for PI children is less than that for the NA children.

\section{CONCLUSION}

These results suggest that stress and growth stunting early in life do not necessarily result in early-onset puberty (for girls) and obesity risk. They raise the possibility that either the early timing of removal from adversity or the later context of rearing in highly resourced homes with highly educated parents may alter and perhaps buffer children from long-term impacts on BMI and early pubertal development. Of course, it will be critical to follow the subsequent waves of data collection on this project to understand growth curves both of body fat and pubertal stage as PI youth progress through adolescence.

\section{ACKNOWLEDGMENTS}

We thank the families for their participation and the International Adoption Project. We thank Tori Simenec, Bao Moua, and Lea Neumann for their assistance with the study, as well as our nurses Janet Goodwalt, Terri Jones, and Melissa Stoll. This material is based on work supported by the National Science Foundation Graduate Research Fellowship under Grant No. (NSF Grant 00039202).

\section{STATEMENT OF FINANCIAL SUPPORT}

This study was funded by Grant Number 5R01 HD075349-02 (to M.G.) from the Eunice Kennedy Shriver National Institute of Child Health \& Human Development (NICHD) at the National Institute of Health (NIH).

\section{DISCLAIMER}

Any opinion, findings, and conclusions or recommendations expressed in this material are those of the authors(s) and do not necessarily reflect the views of the National Science Foundation.

Disclosure: The authors declare no conflict of interest.

\section{REFERENCES}

1. Bateson P, Barker D, Clutton-Brock T, et al. Developmental plasticity and human health. Nature 2004;430:419-21.

2. Popkin BM, Richards MK, Montiero CA. Stunting is associated with overweight in children of four nations that are undergoing the nutrition transition. J Nutr 1996;126:3009-16.

3. Clarkin PF. Adiposity and height of adult Hmong refugees: relationship with war-related early malnutrition and later migration. Am J Hum Biol 2008;20:174-84.

4. Villamor E, Jansen EC. Nutritional determinants of the timing of puberty. Annu Rev Public Health 2016;37:33-46.
5. Mendle J, Ryan RM, McKone KM. Early childhood maltreatment and pubertal development: replication in a population-based sample. J Res Adolesc 2016;26:595-602.

6. Mendle J, Leve LD, Van Ryzin M, Natsuaki MN, Ge X. Associations between early life stress. Child maltreatment, and pubertal development among girls in foster care.. J Res Adolesc 2011;21:871-0.

7. Boynton-Jarrett R, Wright RJ, Putnam FW. Childhood abuse and age at menarche. J Adolesc Health 2013;52:241-7.

8. Johnson DE, Gunnar MR IV. Growth failure in institutionalized children. Monogr Soc Res Child Dev 2011;76:92-126.

9. Johnson DE. Long-term medical issues in international adoptees. Pediatr Ann 2000;29:234-41.

10. Kroupina MG, Eckerle JK, Fuglestad AJ, et al. Associations between physical growth and general cognitive functioning in international adoptees from Eastern Europe at 30 months post-arrival. J Neurodev Disord 2015;7:36.

11. Miller BS, Kroupina MG, Mason P, et al. Determinants of catch-up growth in international adoptees from Eastern Europe. Int J Pediatr Endocrinol 2010;2010:107252.

12. Monk C, Georgieff MK, Osterholm EA. Research review: maternal prenatal distress and poor nutrition - mutually influencing risk factors affecting infant neurocognitive development. J Child Psychol Psychiatry 2013;54:115-30.

13. Adair LS. Size at birth and growth trajectories to young adulthood. Am J Hum Biol 2007;19:327-7.

14. Lucas A, Fewtrell MS, Cole TJ. Fetal origins of adult disease-the hypothesis revisited. BMJ 1999;319:245-9.

15. Sawaya AL, Roberts S. Stunting and future risk of obesity: principal physiological mechanisms. Cad Saude Publica 2003;19:S21-8.

16. Monteiro PO, Victora CG. Rapid growth in infancy and childhood and obesity in later life-a systematic review. Obes Rev 2005;6: 143-54.

17. Golub MS, Collman GW, Foster PM, et al. Public health implications of altered puberty timing. Pediatrics 2008;121:S218-30.

18. Downing J, Bellis MA. Early pubertal onset and its relationship with sexual risk taking, substance use and anti-social behaviour: a preliminary cross-sectional study. BMC Public Health 2009;9:446.

19. Dunbar J, Sheeder J, Lezotte D. Age at menarche and first pregnancy among psychosocially at-risk adolescents. Am J Public Health 2008;98: $1822-4$.

20. Glynn JR, Kayuni N, Gondwe L, Price AJ, Crampin AC. Earlier menarche is associated with a higher prevalence of Herpes simplex type-2 (HSV-2) in young women in rural Malawi. Elife 2014;3:e01604.

21. Proos LA. Growth \& development of Indian children adopted in Sweden. Indian J Med Res 2009;130:646-50.

22. Teilmann G, Pedersen CB, Skakkebaek NE, Jensen TK. Increased risk of precocious puberty in internationally adopted children in Denmark. Pediatrics 2006;118:e391-9.

23. Partsch CJ, Sippell WG. Pathogenesis and epidemiology of precocious puberty. Effects of exogenous oestrogens. Hum Reprod Update 2001;7: 292-302.

24. Mul D, Oostdijk W, Drop SL. Early puberty in adopted children. Horm Res 2002;57:1-9.

25. Krstevska-Konstantinova M, Charlier C, Craen M, et al. Sexual precocity after immigration from developing countries to Belgium: evidence of previous exposure to organochlorine pesticides. Hum Reprod 2001;16: $1020-6$.

26. Hayes P, Tan TX. Timing of menarche in girls adopted from China: a cohort study. Child Care Health Dev 2016;42:859-62.

27. Mason P, Narad C. Long-term growth and puberty concerns in international adoptees. Pediatr Clin North Am 2005;52:1351-68.

28. de Onis M, Onyango AW, Borghi E, Siyam A, Nishida C, Siekmann J. Development of a WHO growth reference for school-aged children and adolescents. Bull World Health Organ 2007;85:660-7.

29. Dempster P, Aitkens S. A new air displacement method for the determination of human body composition. Med Sci Sports Exerc 1995;27:1692-7. 


\section{Articles | Reid et al.}

30. Marshall WA, Tanner JM. Variations in pattern of pubertal changes in girls. Arch Dis Child 1969;44:291-303.

31. Marshall WA, Tanner JM. Variations in the pattern of pubertal changes in boys. Arch Dis Child 1970;45:13-23.

32. Carskadon MA, Acebo C. A self-administered rating scale for pubertal development. J Adolesc Health 1993;14:190-5.

33. Petersen AC, Crockett L, Richards M, Boxer A. A self-report measure of pubertal status: reliability, validity, and initial norms. J Youth Adolesc 1988;17:117-33.

34. Ogden CL, Carroll MD, Kit BK, Flegal KM. Prevalence of childhood and adult obesity in the United States, 2011-2012. JAMA 2014;311: 806-14.

35. Walker SP, Chang SM, Powell CA. The association between early childhood stunting and weight status in late adolescence. Int J Obes 2007;31:347-52.
36. Schwandt $\mathrm{P}$, Haas GM. Is the ratio waist circumference to height (WHtR) of 0.5 a universal measure for abdominal adiposity in children and adolescents? Int J Obes 2016;40:1141-2.

37. Skidmore PM, Cassidy A, Swaminathan R, et al. An obesogenic postnatal environment is more important than the fetal environment for the development of adult adiposity: a study of female twins. Am J Clin Nutr 2009;90:401-6.

38. Addo OY, Miller BS, Lee PA, Hediger ML, Himes JH. Age at hormonal onset of puberty based on luteinizing hormone, inhibin B, and body composition in preadolescent U.S. girls. Pediatr Res 2014;76:564-70.

39. Zhang YX, Zhao JS, Chu ZH. Children and adolescents with low body mass index but large waist circumference remain high risk of elevated blood pressure. Int J Cardiol 2016;215:23-5.

40. Gonzalez-Barranco J, Rios-Torres JM. Early malnutrition and metabolic abnormalities later in life. Nutr Rev 2004;62:S134-9. 